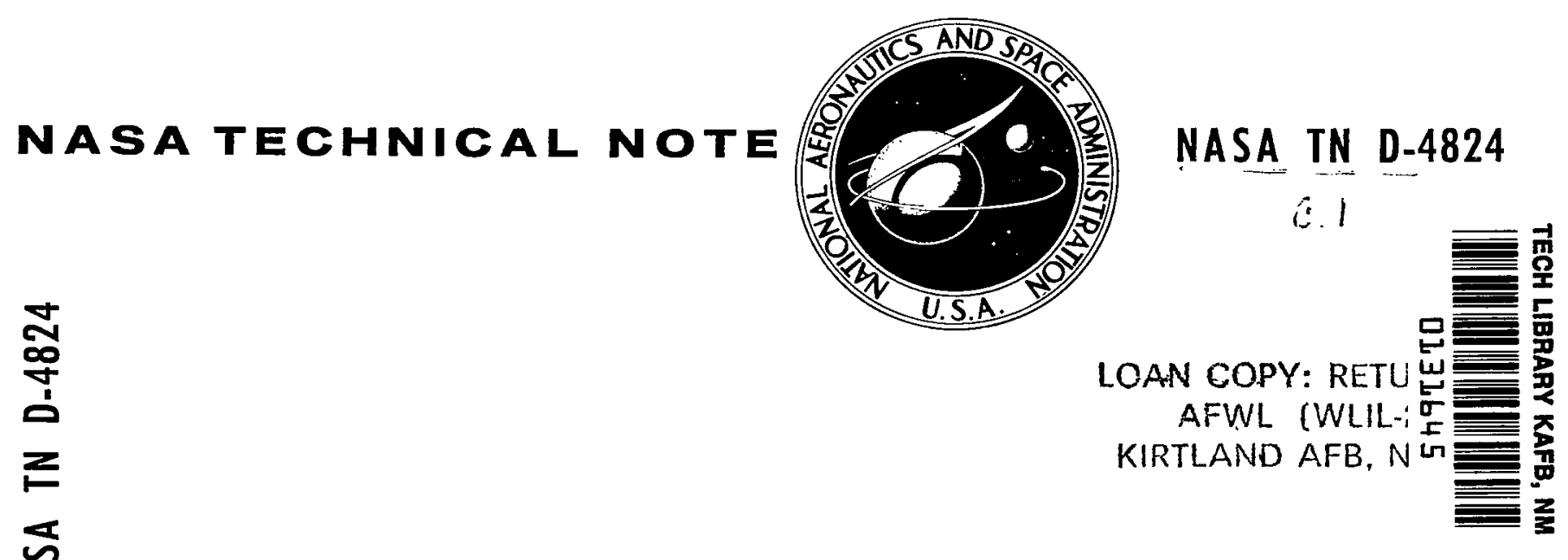

\title{
SLIDING FRICTION OF COPPER ALLOYS IN VACUUM
}

by Jane Jellison, Roamer Predmore, and C. L. Staugaitis

Goddard Space Flight Center

Greenbelt, $M d$.

NATIONAL AERONAUtICS AND SPACE AdMINISTRATION - WASHINGTON, D. C: • NOVEMBER 1968 


\section{SLIDING FRICTION OF COPPER}

\section{ALLOYS IN VACUUM}

By Jane Jellison, Roamer Predmore, and C. L. Staugaitis

Goddard Space Flight Center

Greenbelt, Md. 


\begin{abstract}
Sliding friction experiments involving copper and $\mathrm{Cu}-\mathrm{Be}$ alloy plates in contact with copper, $\mathrm{Cu}-\mathrm{Be}$ alloy, steel and titanium alloy sliders were performed in air and vacuum. Microhardness and metallographic examination of plate and slider interface suggests friction and wear by the adhesive friction mechanism with prow formation. Transfer of strain-hardened metal wear debris across the sliding interface was observed. The friction coefficient and the prow size generally increased in vacuum.
\end{abstract}




\section{CONTENTS}

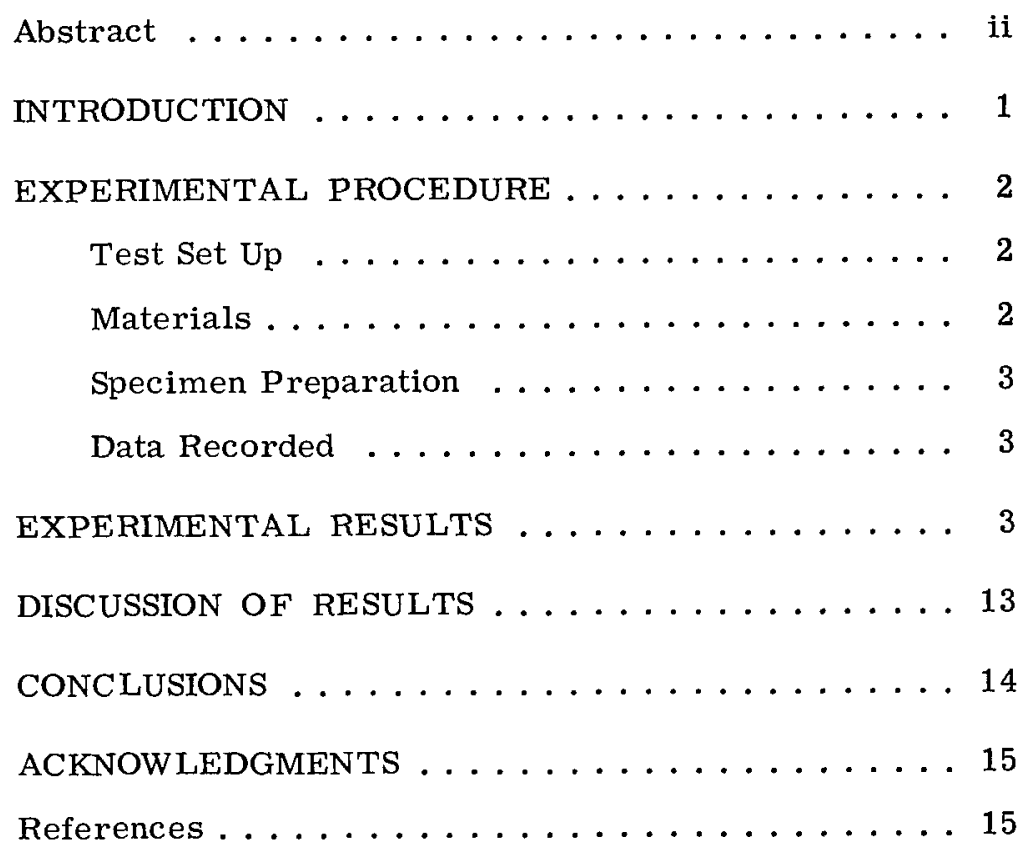




\title{
SLIDING FRICTION OF COPPER ALLOYS IN VACUUM
}

\author{
by \\ Jane Jellison, Roamer Predmore, C. L. Staugaitis \\ Goddard Space Flight Center
}

\section{INTRODUCTION}

The behavior of metal surfaces in sliding contact is increasingly important to the spacecraft designer, as space environments continue to make demands for longer service lifetimes.

Evans and Monroe (Reference 1) reviewed researches made on the problem of surface welding in high vacuum. These studies indicated that some dynamic friction coefficients of 30 pure metals sliding on themselves at $1 \mathrm{~mm}$ per second could reach values as high as 6.5 in high vacuum at ambient temperatures. The studies also presented the adhesion bond strengths developed by copper-copper ( $\mathrm{Cu}-\mathrm{Cu})$ couples and other alloy metals. Buckley (Reference 2) has measured dynamic friction coefficients for a variety of metals in high vacuum and correlated these results with crystal structure, orientation, and applied load. Johnson and Keller (Reference 3) have measured the adhesion developed between clean copper and nickel, copper and copper, and other metal couples in high vacuum.

Rabinowicz (Reference 4) discussed the effects of metal solubility, metal oxide, and crystal structure in his review of the adhesion theory of friction. Cocks (References 5, 6, and 7) has described the growth of wedges or prows between sliding metal interfaces and their role in sliding friction in air. Ling (Reference 8) described the role of continuum mechanics in the mechanism of metallic surface friction in air. Bowden (Reference 9 ) et al. showed fragments of slider metal that was cold-welded to the wear tracks. Keller (Reference 10) reviewed metaladhesion data that he had obtained and related them to the theories of friction and prow or wedge formation.

The primary objective of this study is to investigate the friction and wear behavior of a variety of metal couples in air and vacuum. The specific role of wedge formation and attendant plastic deformation in relation to work hardening phenomena and cold welding propensity are investigated from the mechanical and metallurgical points of view. This study covers the coppercopper beryllium group of wear plates tested with sliders from the copper, iron, and titanium groups. 


\section{EXPERIMENTAL PROCEDURE}

\section{Test Set Up}

The apparatus for friction testing was of the disc-and-rider type, with the plate specimen (a 4-1/2-inch diameter disc mounted on a turntable) driven by a 6-rpm sealed bearing motor, and the slider 1/4 inch in diameter having a hemispherical tip. A dead-weight normal load of 1 pound was selected, because of the relatively constant relation between coefficient of friction versus load at this load level (Reference 11). A strain gauge mounted near the base of the slider arm enabled the friction force to be recorded continuously as the test progressed. The test device and recording system covered the range of coefficients from zero to 2.0. (This range was limited by the recorder scale selected and not by the strain-gauge instrumentation.)

Employing identical sliders, three separate tests were conducted on each plate material at pressures of 760 torr, $10^{-4}$ torr, and $10^{-8}$ torr. By successive reduction of slider-arm radius by $3 / 16$ inch, three different wear tracks were generated on a single plate. The use of one plate and three to five identical sliders assures material constancy from one environmental pressure to another. The three standard test conditions were:

(1) 25 revolutions in air

(2) 25 revolutions at $10^{-4}$ torr

(3) 25 revolutions at $10^{-8}$ torr.

In a few cases, tests of one revolution only were run in air and vacuum. Sliding speed for all tests was approximately $2.5 \mathrm{~cm}$ per second, to limit the interface temperature rise to at most several degrees (Reference 12). The entire test assembly was mounted in a Stokes Vacuum Chamber with an 18 - by 24 -inch glass bell jar, pumped by 4 -inch and 10 -inch oil-diffusion pumps, a liquid-nitrogen baffle, and a mechanical forepump.

At intervals during the test program, glass slides were placed in the chamber to check for oil contamination. Infrared spectroscopy analysis of washings from a slide, cycled five times from atmospheric pressure to $10^{-8}$ torr, showed no residue. Recent studies of backstreaming from diffusion vacuum pumps show no evidence of oil contamination. ${ }^{*}$ Thus, contamination by backstreaming vacuum pump oil did not affect the test results.

\section{Materials}

Plate materials in the copper-base alloy group included copper and copper-beryllium alloy 25, in annealed, strain hardened, and precipitation hardened conditions. The sliders were copper, copper-beryllium, titanium, and steel. Table 1 lists the designations and hardnesses of these materials, which were selected to give a range of mechanical properties.

* Shapiro, H., Goddard Space Center, Private Communication. 


\section{Specimen Preparation}

Wear plates were polished metallographically before testing; sliders were polished in the tip area. Immediately before testing, plates and sliders were lightly repolished and cleaned ultrasonically in acetone or alcohol. Specimens were mounted in the test fixture, the test run in air performed, and the chamber evacuated immediately.

\section{Data Recorded}

The coefficient of friction and number of revolutions were recorded on a dual-pen Honeywell Recorder continuously throughout the test. Specimens were examined visually at magnifications from 10 to 50 . The presence of transferred material and the extent of wear were recorded for sliders and wear tracks. Selected specimens were sectioned for metallographic analysis-sliders longitudinally, parallel to the direction of motion. Plates were sectioned perpendicular to the wear tracks and mounted at a shallow angle, as described by Bowden and Tabor (Reference 13). A typical mounting angle of 6 degrees results in vertical magnification by 10 . Etched and unetched specimens were examined for evidence of deformation, metal transfer, strain-hardening, and similar metallurgical variables. Strain-hardening was measured by taking microhardness traverses near and across the test interface. Diamond pyramid hardnesses were obtained from a Reichert microhardness tester with a 15-gram load.

\section{EXPERIMENTAL RESULTS}

The maximum dynamic coefficient of friction (hereafter referred to as friction coefficient) for titanium, steel, copper, and $\mathrm{Cu}-\mathrm{Be}$ sliders on copper and $\mathrm{Cu}-\mathrm{Be}$ plates are graphically summarized in Figure 1 and listed in Table 2. Despite the apparent scatter in data, it is evident that the friction coefficient generally decreases with increasing plate hardness.

Figure 2 presents the friction coefficient versus test-chamber pressure for the same material combinations. The friction coefficient for $\mathrm{Cu}$ and $\mathrm{Cu}-\mathrm{Be}$ sliders on copper plates was 
Table 2

Maximum Coefficient of Friction for Copper-Base Plates.

\begin{tabular}{|c|c|c|c|c|c|c|c|c|c|c|c|c|}
\hline \multirow{3}{*}{ Slider } & \multicolumn{12}{|c|}{ Plates } \\
\hline & \multicolumn{3}{|c|}{$\begin{array}{l}\text { Copper } \\
\text { RF } 50-70\end{array}$} & \multicolumn{3}{|c|}{$\begin{array}{c}\mathrm{Cu}-\mathrm{Be} \text { Annealed } \\
\text { RB } 50\end{array}$} & \multicolumn{3}{|c|}{$\begin{array}{c}\mathrm{Cu}-\mathrm{Be} 1 / 4 \mathrm{H} \\
\mathrm{RB} 60-85\end{array}$} & \multicolumn{3}{|c|}{$\begin{array}{c}\mathrm{Cu}-\mathrm{Be} 1 / 4 \mathrm{HT} \\
\mathrm{RC} 38-41\end{array}$} \\
\hline & $\mu \max _{760}$ & $\frac{\mu \max }{10^{-4}}$ & $\mu \max _{10^{-8}}$ & $\mu \max _{760}$ & ${ }_{10^{-4}}^{\mu \max }$ & $\mu \max _{10^{-8}}$ & $\mu \max _{760}$ & ${ }_{10^{-4}}^{\mu \max }$ & $\mu \max$ & ${ }_{760}^{\mu \max }$ & $\mu \max x$ & $\frac{\mu \max }{10^{-8}}$ \\
\hline $\begin{array}{l}\mathrm{Cu} \\
\mathrm{RF} 75\end{array}$ & 2.0 & & 2.0 & 1.05 & 1.40 & 1.45 & 1.22 & 1.33 & 1.42 & 0.98 & 0.78 & 1.07 \\
\hline $\begin{array}{l}\mathrm{Cu}-\mathrm{Be} \\
\text { Annealed RF } 75\end{array}$ & 2.0 & 2.0 & 2.0 & 1.20 & 1.40 & 1.46 & 1.70 & 1.42 & 1.66 & 1.09 & 0.88 & 1.13 \\
\hline $\begin{array}{l}\mathrm{Cu}-\mathrm{Be} 1 / 4 \mathrm{HT} \\
\mathrm{RC} 38\end{array}$ & 1.92 & 2.0 & 1.90 & 1.34 & 1.34 & 1.39 & 1.45 & 1.35 & 1.40 & 0.82 & 1.00 & 1.20 \\
\hline $\begin{array}{l}1020 \text { Steel } \\
\text { RB } 87\end{array}$ & 0.55 & 2.0 & 1.85 & & & & 1.20 & 1.25 & 1.18 & 0.84 & & 0.84 \\
\hline $\begin{array}{l}1095 \text { Steel } \\
\text { RC } 38\end{array}$ & 1.30 & & 2.0 & & & & 1.37 & & 1.34 & 0.89 & & 0.91 \\
\hline $\begin{array}{l}1095 \text { Steel } \\
\text { RC } 60\end{array}$ & 1.31 & 1.82 & 1.86 & & & & 1.18 & 1.23 & 1.22 & 1.01 & & 0.96 \\
\hline $\begin{array}{l}\text { Titanium } \\
\text { Com. Pure RB } 90\end{array}$ & 1.54 & & 1.97 & & & & & & & & & \\
\hline $\begin{array}{l}\text { Titanium } 6 \text { al- } 4 \mathrm{~V} \\
\text { RC } 38\end{array}$ & 0.76 & & 2.0 & & & & 1.23 & & 1.40 & 1.07 & & 0.89 \\
\hline
\end{tabular}


about 2.0 for all test conditions. The wear characteristics of this particular metal couple were primarily of the adhesive type, with extensive wedge or prow formation as described by Cocks (Reference 6). (In this report the terms "wedge" and "prow" are used interchangeably.) Figure 3 shows photographically a typical example of this wear mechanism involving $\mathrm{Cu}$ sliders on $\mathrm{Cu}$ plates. The friction coefficient and the appearance of the prows on the sliders are essentially the same in both instances. The wear tracks, one of which is shown, were also very similar. The tracks are wide and rough, and show ragged edges on individual tracks generated by one revolution of the plate. The lower center of Figure 3(b) shows an asperity or prow that has broken off the slider and become embedded in the plate.

While the friction coefficient for most steel and titanium sliders on copper plates increased from approximately 1.4 to 2.0 as pressure decreased from 760 to $10^{-8}$ torr, two exceptions were noted. At atmospheric

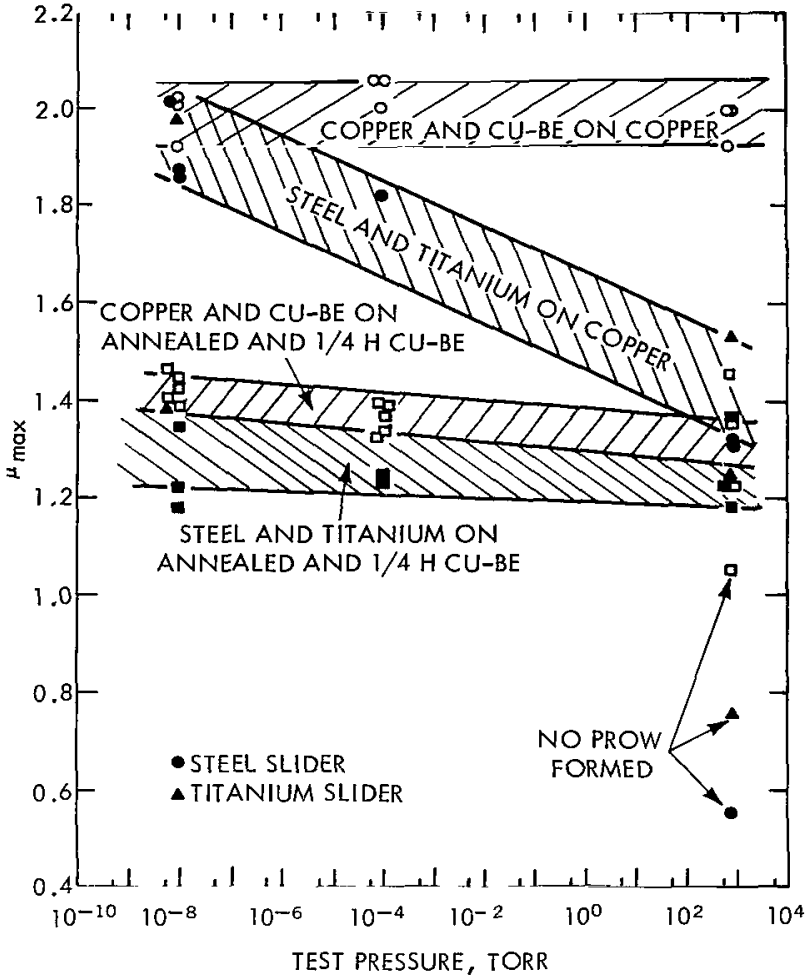

Figure 2-Maximum coefficient of friction vs vacuum for various sliders on soft copper and copper-alloy plates. pressure, a steel and a titanium slider on copper plates had maximum coefficients of friction of about 0.6 and 0.8 , respectively. In both cases the primary mode of wear seemed caused by slider shear rather than prow formation. The same slider materials on $\mathrm{Cu}-\mathrm{Be}$ plates developed wear by an adhesion-prow-formation mechanism, but the friction coefficients were generally much lower than on copper plates, with a maximum of about 1.4 at $10^{-8}$ torr.

Figure 4 shows hardened 1095 steel sliders tested on copper, together with wear tracks. Both sliders have copper prows, but that formed at $10^{-8}$ torr is much larger, both in radial extent and in height. The wear track in vacuum, Figure 4(d), is wider than that formed in air and the individual tracks more ragged. The friction coefficient rose from 1.3 in air to 1.9 at $10^{-8}$ torr. Similar results were obtained with titanium sliders on copper plates. The increase in friction, prow size, and track width with vacuum are characteristic of adhesive friction with prow formation. Oxidation during the sliding in air interferes with the formation of the prow and retards its growth.

While no prow developed in air with a low-carbon steel on a copper plate, prow formation was observed when the metal couple was tested in vacuum. Figure 5 illustrates this behavior. The slider tested in air, part (a), did not form a prow of transferred plate material and shows but a slight amount of wear. The corresponding track is shallow and light, part (b). The friction coefficient was low, about 0.6 , and uniform throughout the test. When tested in vacuum, the slider 


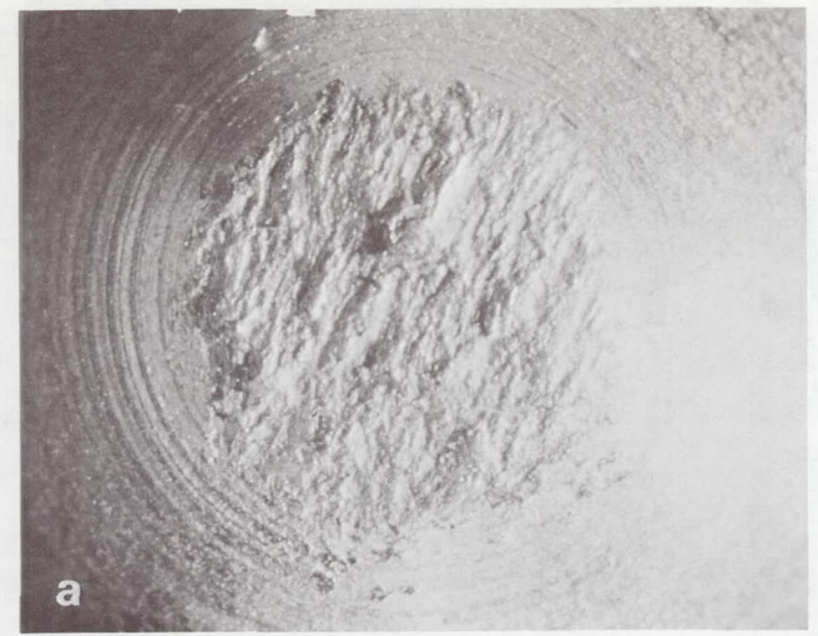

Slider Tested at 760 Torr X20

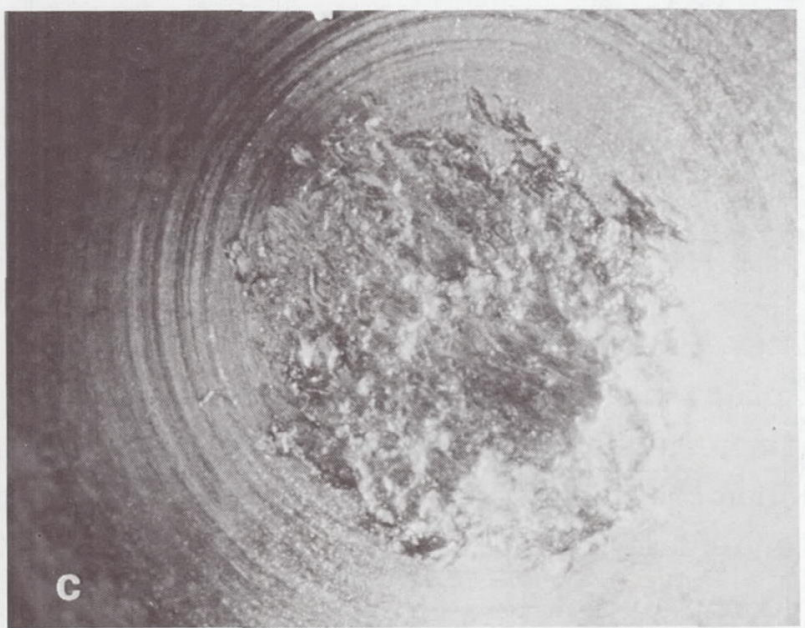

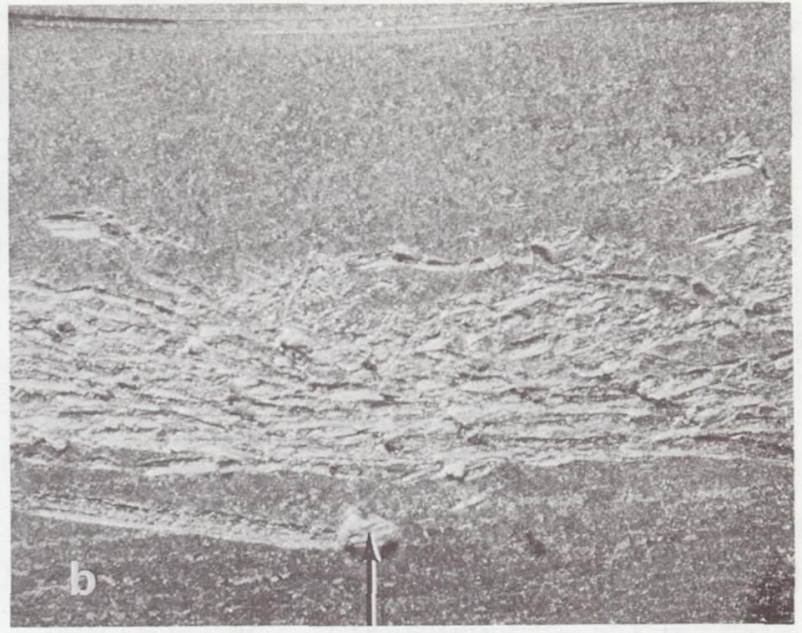

Track for Test in Air. X10

Figure 3-Copper sliders tested on copper plate at 760 and $10^{-8}$ torr. Both formed large prows and developed friction coefficient of 2.0 .

Slider Tested at $10^{-8}$ Torr. $\times 20$

formed a large copper prow; the prow, track appearance and high friction, parts (e) and (f), were similar to those exhibited by the hard steel and titanium sliders previously shown in Figure 4 . For the first revolution, the recorded friction level was low and smooth; at the beginning of the second revolution, prow formation was initiated coincident with an abrupt increase in the coefficient of friction to near maximum value. An additional slider was run for 1-1/2 revolutions in vacuum and then examined. A small, worn area is visible on the rider, partially obscured by a small copper prow, Figure 5(c). The corresponding wear track shows the two types of individual wear tracks associated with the two types of frictional behavior: the inner, low friction track is smooth and shallow, while the track corresponding to the high-friction, adhesive portion of the test is deeply gouged into the plate. 


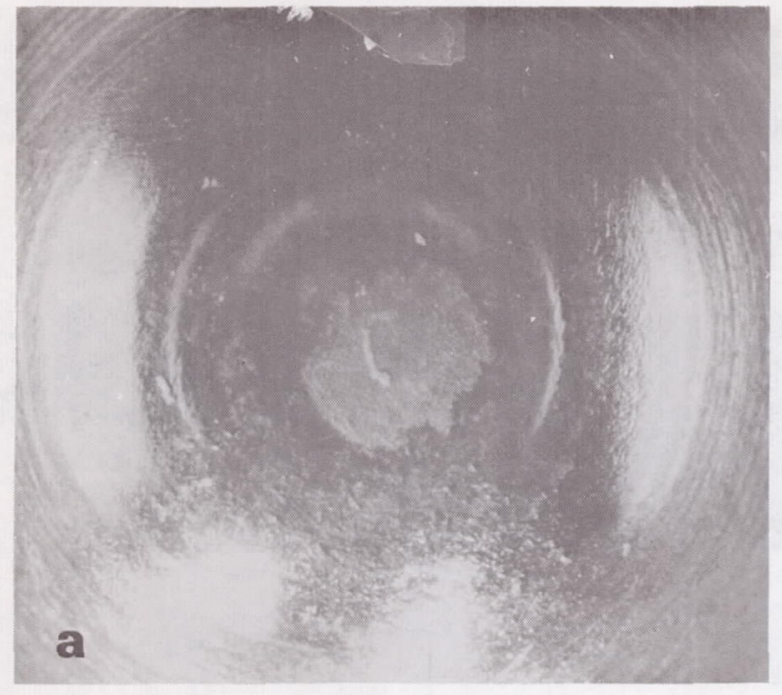

Slider Tested at 760 Torr, 25 Revolutions. $\mu_{\text {max }}=1.31$ (see track 1 at right) $20 \times$

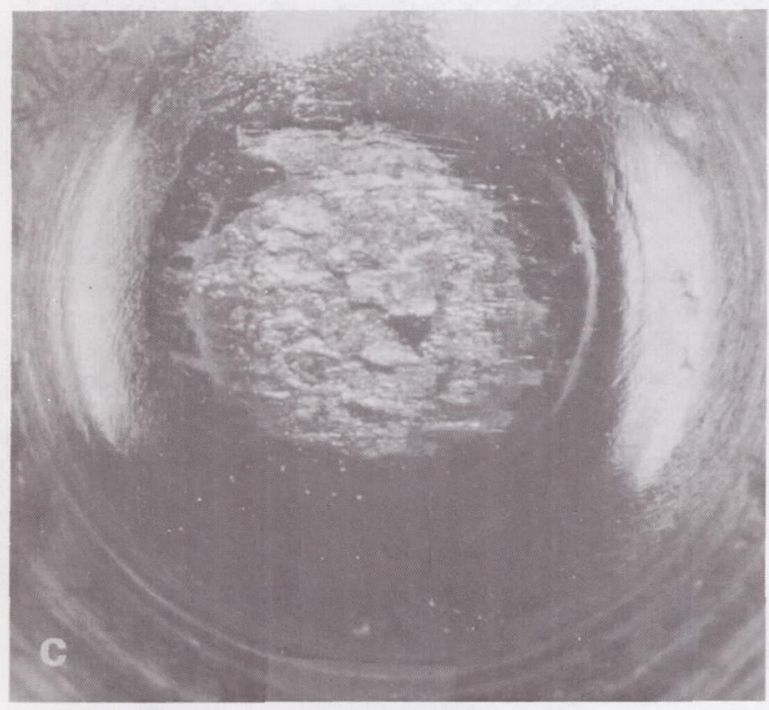

Slider Tested at $10^{-8}$ Torr, 25 Revolutions. $\mu_{\text {max }}=1.86$ (see track 4 at right) $20 \times$

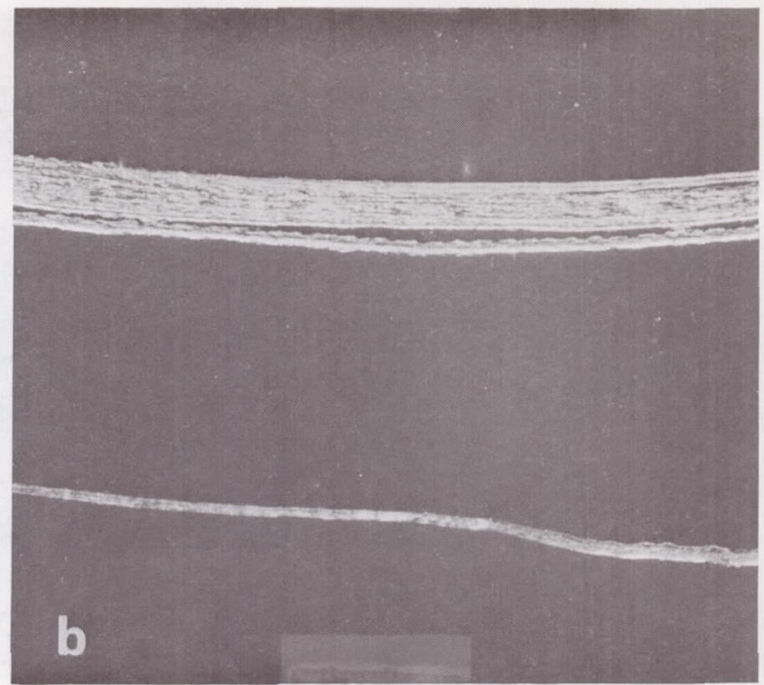

Track 1 (top). 25 Revolutions at 760 Torr. Track 2 (bottom) 1 Revolution. $10 \mathrm{X}$

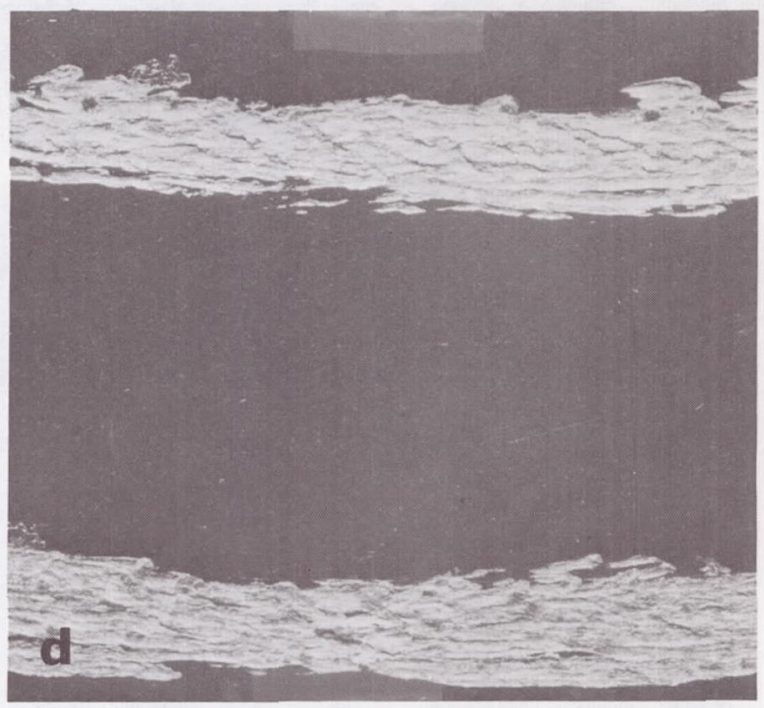

Track 3 (top) 25 Revolutions at $10^{-4}$ Torr Track 4 (bottom) 25 Revolutions at $10^{-8}$ Torr. $10 \mathrm{X}$

Figure 4-1095 steel sliders RC 60 tested on copper plate, at 760 and $10^{-8}$ torr. Both developed prows; that at $10^{-8}$ torr was larger, and friction coefficient increased from 1.31 to 1.86 .

Figure 6 shows a cross section of a copper slider tested on annealed $\mathrm{Cu}-\mathrm{Be}$ at $10^{-8}$ torr. The starting hardness of slider and plate were nearly equal; shear occurred alternately on either side of the cold-welded junction. The prow in Figure 6 has a laminated structure resulting from this alternating fracture site. The track, Figure 7, has particles of copper embedded in it and shows 

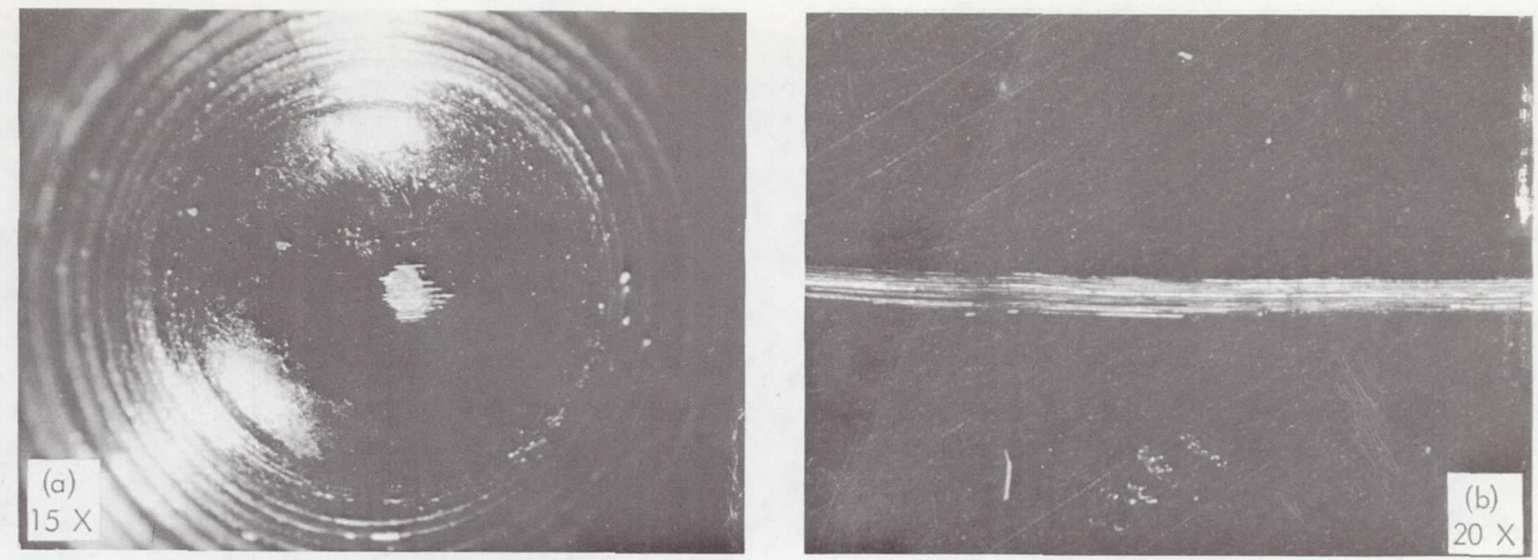

(a), (b): 25 revolutions at 760 torr. $\mu_{\text {max }}=0.6$.
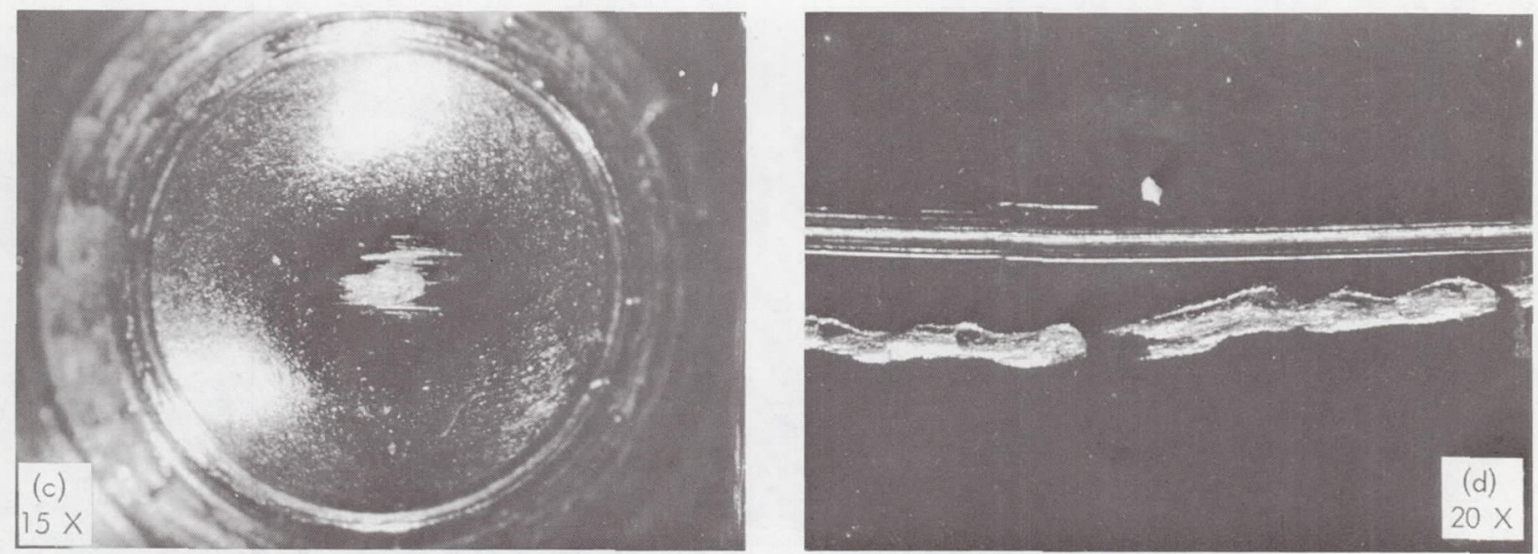

(c), (d): $11 / 2$ revolutions at $10^{-4}$. At end of 1 st revolution, $\mu$ increased abruptly from 0.5 to 1.8 .
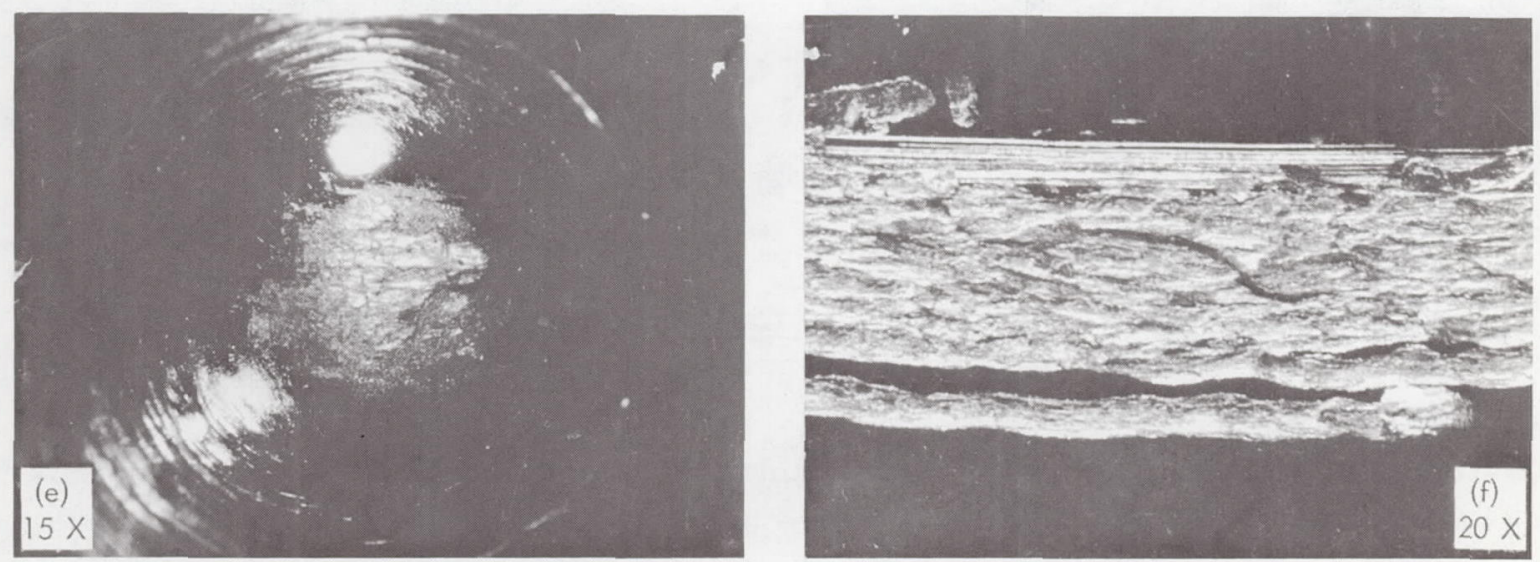

(e), (f) : 25 revolutions at $10^{-8}$ torr. $\mu$ max $=1.9$. Smooth, low-friction track from first revolution is visible at top of part (f).

Figure 5-1020 steel tested on copper. 


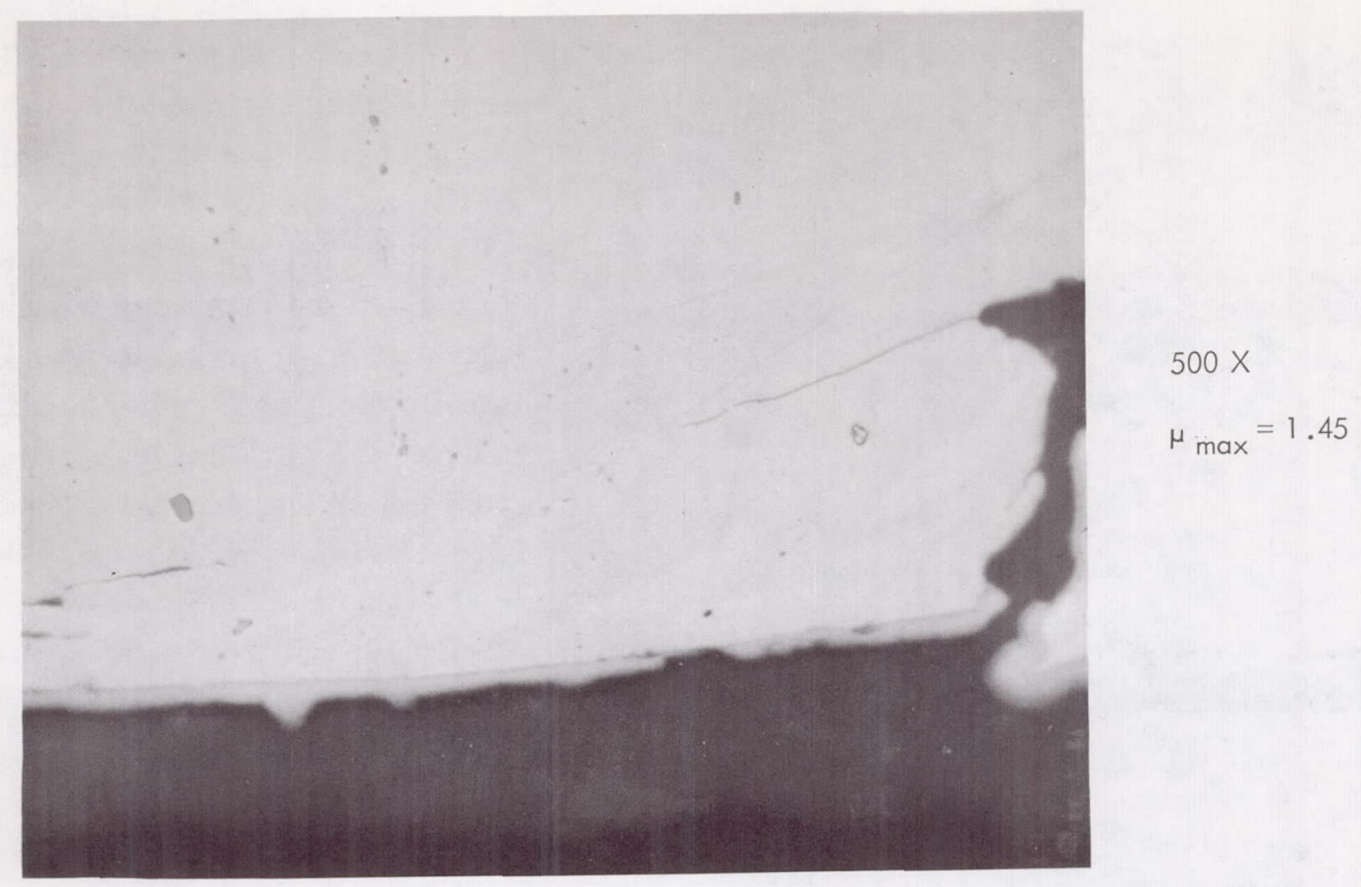

Figure 6-Copper slider tested on annealed $\mathrm{Cu}$-Be plate. Prow is composed of both slider and plate material.

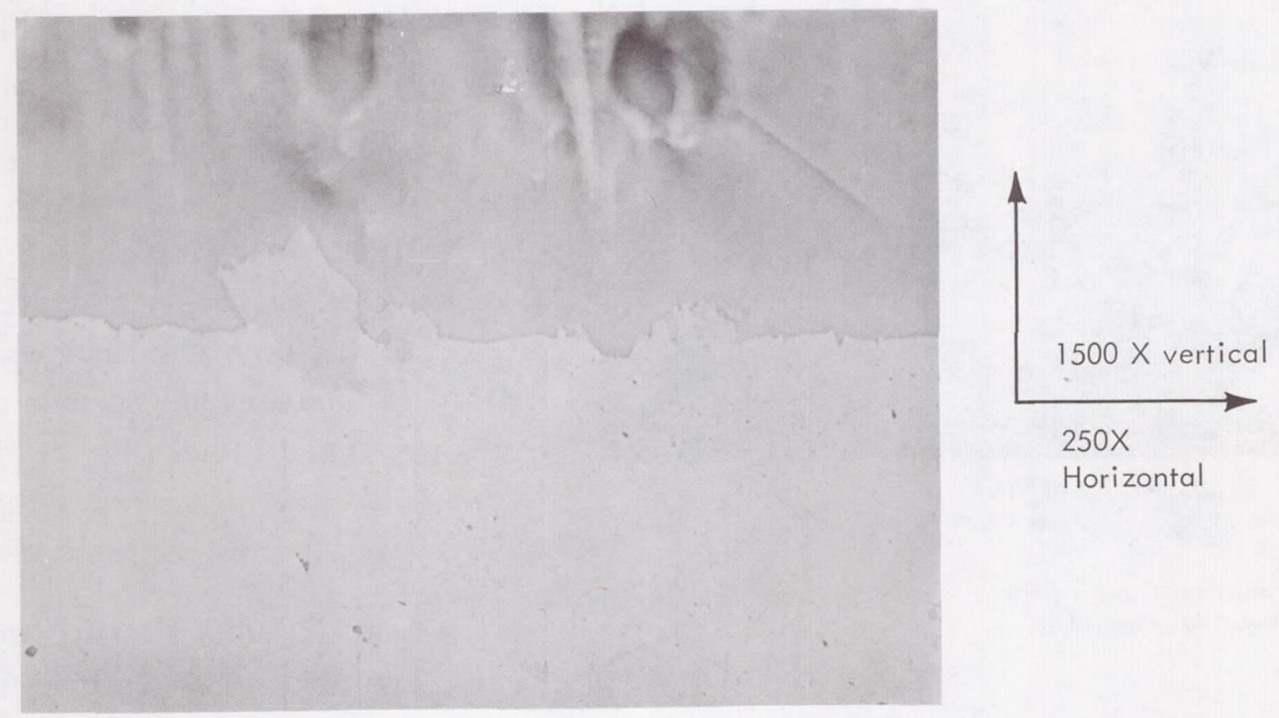

Figure 7-Portion of wear track on $\mathrm{Cu}$-Be plate tested with copper slider above. Plate metal has been pulled out and copper from the slider has adhered to the plate.

evidence of craters resulting from $\mathrm{Cu}-\mathrm{Be}$ being extracted from this plate material. Note the soundness of the cold-welded junction; only the color difference renders it visible. In other cases, such as $\mathrm{Cu}-\mathrm{Be}$ sliding on $\mathrm{Cu}-\mathrm{Be}$, the junction line is completely invisible in the unetched condition, even under high magnification. 


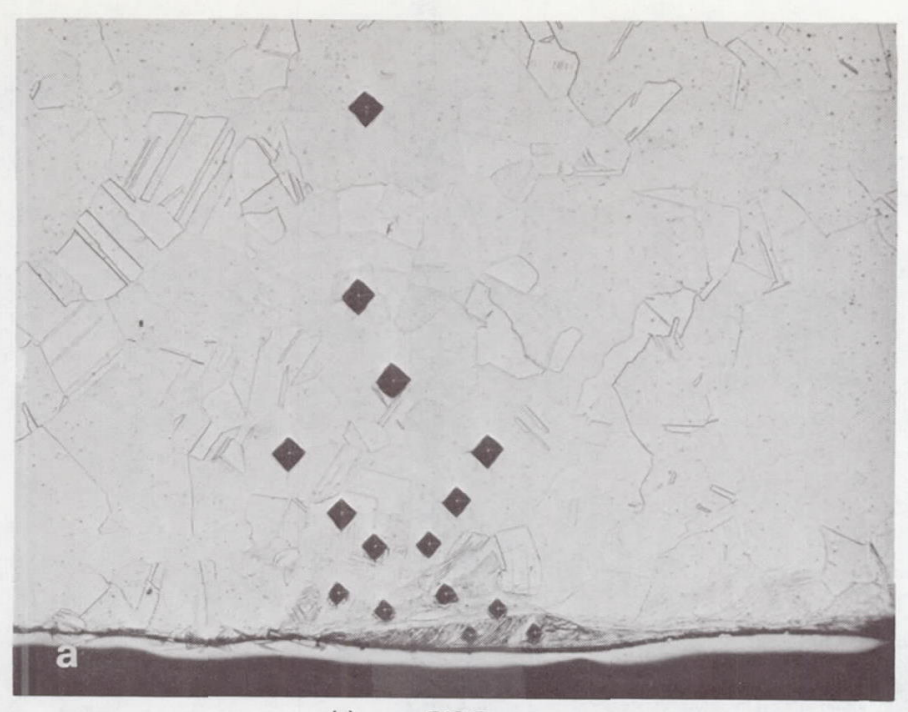

(a)

$$
\begin{aligned}
& 760 \text { Terr } \\
& \mu_{\max }=1.20
\end{aligned}
$$

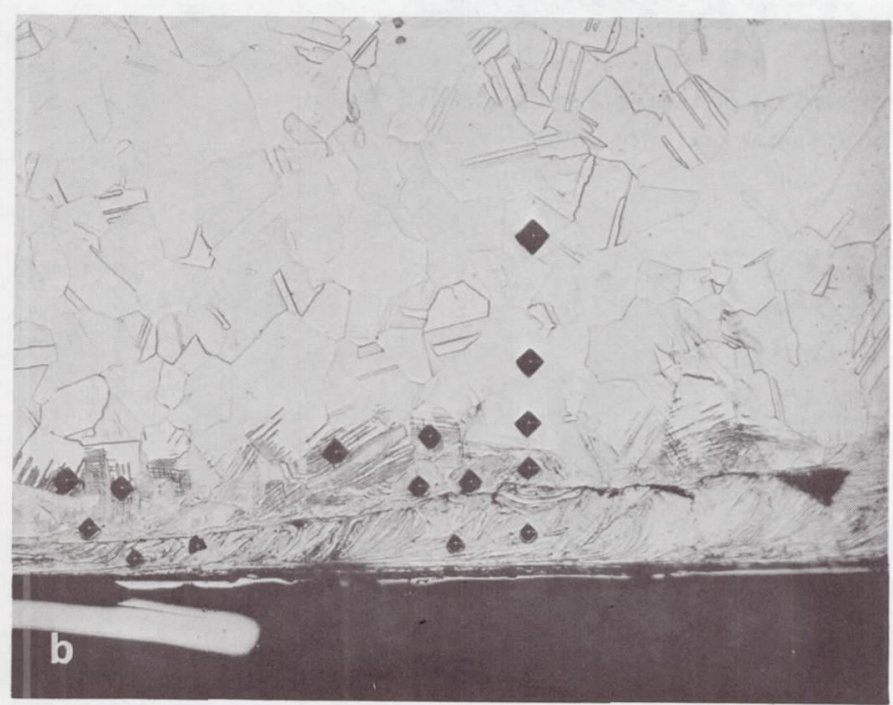

(b)

$10^{-8}$ Torr

$$
\mu \max =1.46
$$

Figure 8-Annealed $\mathrm{Cu}-\mathrm{Be}$ sliders tested on annealed $\mathrm{Cu}-\mathrm{Be}$ plate. Prow developed in vacuum is larger. $350 \mathrm{X}$.
Figure 8 illustrates the effect of vacuum on the deformation and prow formation processes for annealed $\mathrm{Cu}-\mathrm{Be}$ sliding on annealed $\mathrm{Cu}-\mathrm{Be}$. Going from air to vacuum, the prow became much larger and the maximum coefficient of friction rose from 1.2 to 1.5. Slip lines in both sliders and plate, Figures 8 and 9, indicate the work hardening resulting from the sliding process. Maximum hardness is observed in the severely worked prow material on both sliders, Figure 10, and the decrease with increasing distance from the sliding interface shows no dependence on vacuum. From the geometry of the test setup, all sliders show a greater depth of hardening than corresponding tracks on the plate. However, while the depth of slider hardening remains the same in air and in vacuum, the disturbed area is much larger for the slider tested in vacuum (see Figure 8 ).

Figure 11 illustrates similar hardening behavior for $\mathrm{Cu}-\mathrm{Be}$ and copper plates tested with sliders harder than the former. The fully hardened slider materials show no change in hardness, in contrast to the 1/4-H Cu-Be plate that increased from DPH 175 to 400 at the track surface and the copper plate where the hardness increased from DPH 85 within the plate to 200 within the prow on the slider.

Figure 12 plots friction coefficient $\mu$ versus number of revolutions for strain hardenable and fully precipitation-hardened $\mathrm{Cu}-\mathrm{Be}$ plates. These schematic friction traces are plotted from the average values of several plates tested with different slider materials where wear was generated by prow formation of plate material (Table 3 ). While the maximum coefficient of friction for annealed and $1 / 4 \mathrm{H}$ plates is nearly the same in air and in vacuum, the coefficients at the end of the test, here designated $\mu_{25}$, are quite different. At 760 torr, the maximum of 1.33 is reached during the first few revolutions and then decreases, leveling out at about the 15th revolution at an average value of 0.94 and remaining constant thereafter. But at $10^{-8}$ torr the 


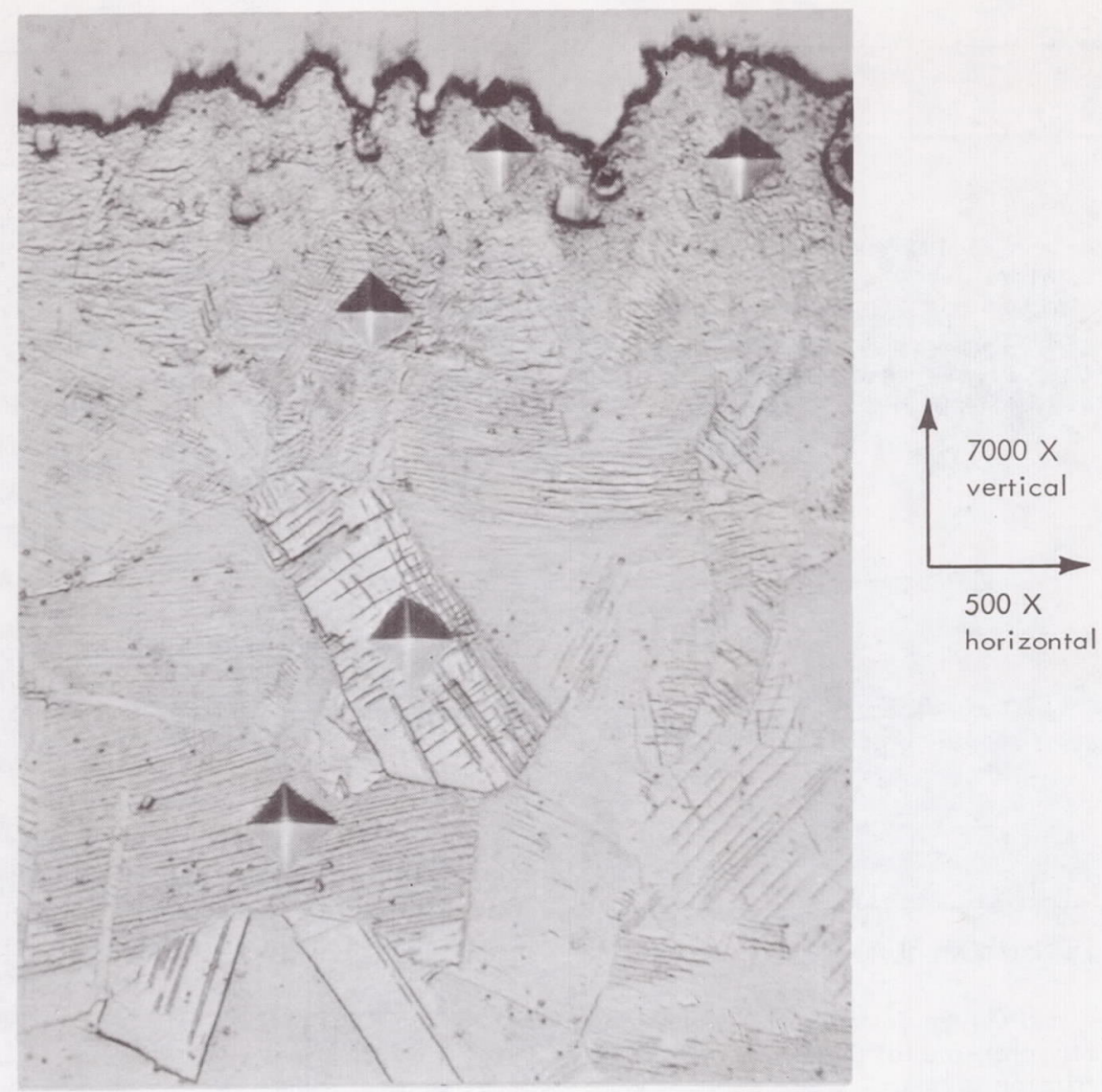

Figure 9-Taper cross section of wear track on annealed $\mathrm{Cu}$-Be plate tested at $10^{-8}$ torr with annealed $\mathrm{Cu}-\mathrm{Be}$ slider (illustrated in Figure 7 ).

maximum, 1.38, occurs much later and tapers off only slightly by the end of the test to an average value of 1.29 . The surface microhardness of all plates increases from the initial DPH range of 110 to 160 to a maximum of about 350 , because of work hardening during the test (Figure 10). The $\mathrm{Cu}-\mathrm{Be}$ prows formed in air were uniformly small, Figure 8(a), and had the same high hardness. The terminal coefficient of friction of 0.94 results from this small, hard prow sliding on the hardened plate surface. The prows formed in vacuum, while equally hard, were invariably larger.

Figure 12 also shows the friction trace for $1 / 4 \mathrm{HT} \mathrm{Cu}-\mathrm{Be}$, which had a starting bulk hardness of DPH 350 . The friction trace rose to a

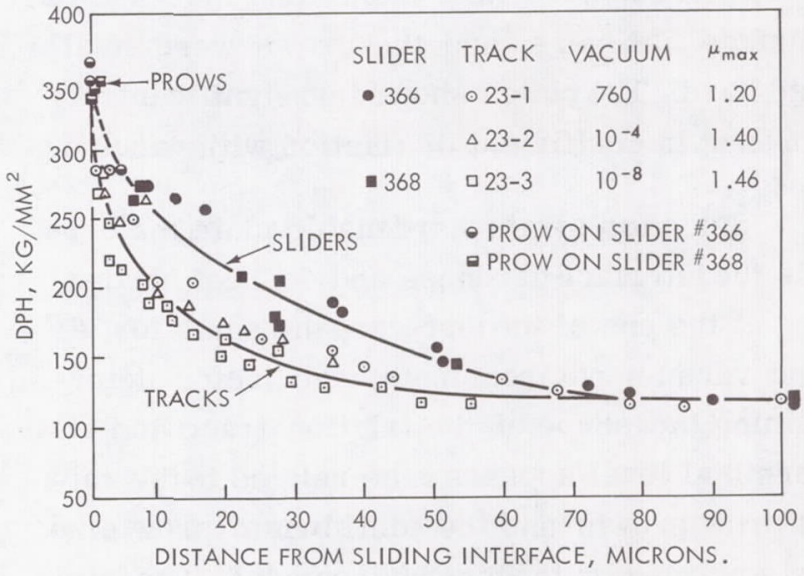

Figure 10-Hardness vs distance from surface for anneal ed $\mathrm{Cu}-\mathrm{Be}$ sliders tested on annealed $\mathrm{Cu}-\mathrm{Be}$ plate. Prows are plotted at distance zero from interface. Curves are plotted from photos in Figures 8 and 9. 


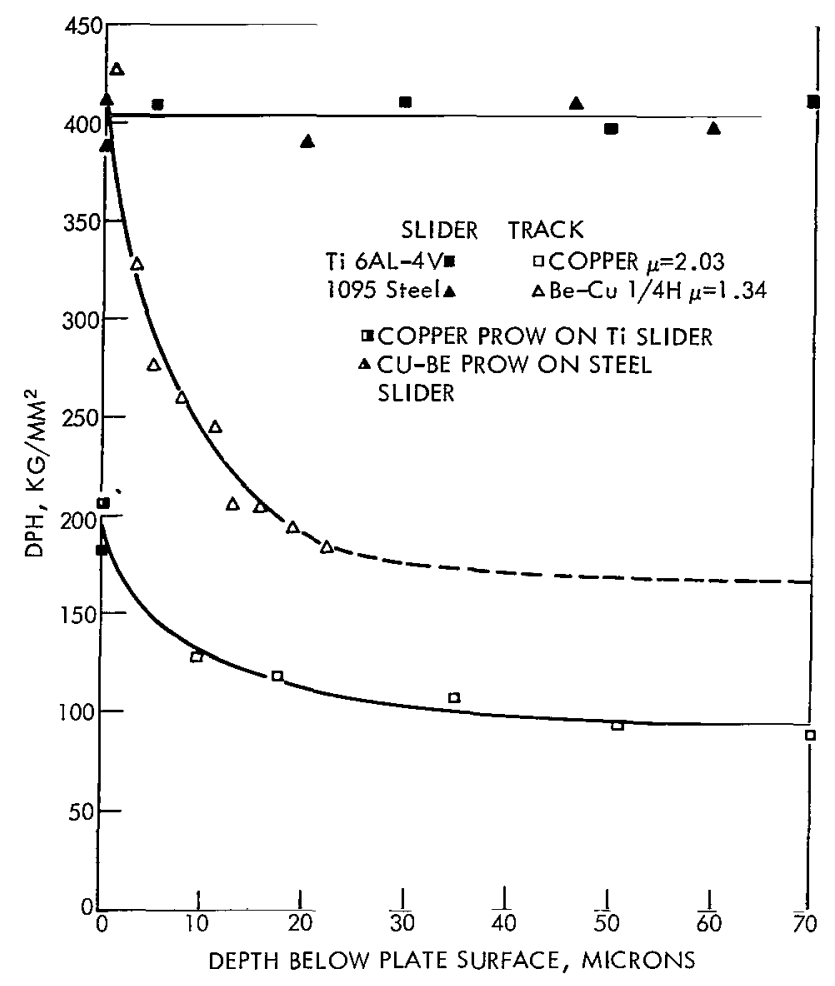

Figure 11-Copper and $\mathrm{Cu}-\mathrm{Be}$ tested with hard sliders. Wear in vacuum is by plate-metal pickup. Cu-Be workhardens more and friction is less.

maximum about halfway through the test and remained nearly constant thereafter in air and in vacuum. The plate material, already fully precipitation hardened, showed no increase in surface hardness, and the prows were small and hard. The plates showed no significant difference in coefficient of friction with vacuum.

Since for strain-hardenable plate materials the interface hardness and depth of hardening at the end of the test were the same for air and vacuum environments, the factor determining the shape of the friction trace and its terminal level appears to be related to the rate of prow growth and the equilibrium prow size as governed by the test environment. The fric-

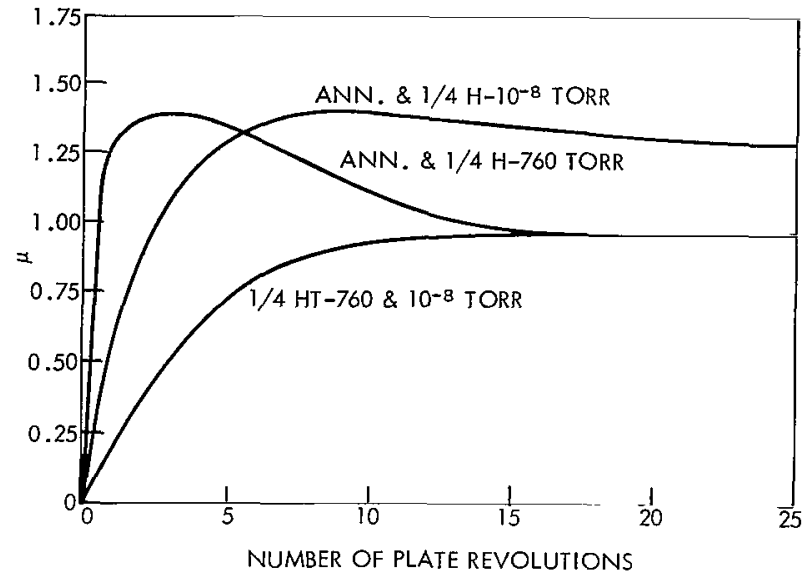

Figure 12-Schematic friction traces for $\mathrm{Cu}-\mathrm{Be} 1 / 4 \mathrm{H}$ and $1 / 4 \mathrm{HT}$ in air and at $10^{-8}$ torr. $\mu_{\max }$ and $\mu_{25}$ are average values taken from Table 3.

\section{Table 3}

Maximum and Terminal Coefficients for Annealed, Quarter-Hard, and Precipitation-Hardened $\mathrm{Cu}-\mathrm{Be}$ Plates Tested in Air and Vacuum with Various Slider Materials

\begin{tabular}{|l|c|c||c|c|}
\hline \multirow{2}{*}{ Plate } & \multicolumn{2}{|c||}{760 Torr } & \multicolumn{2}{c|}{$10^{-8}$ Torr } \\
\cline { 2 - 5 } & $\mu_{\mathrm{max}}$ & $\mu_{25}$ & $\mu_{\mathrm{max}}$ & $\mu_{25}$ \\
\hline Annealed & 1.20 & 1.11 & 1.46 & 1.40 \\
(DPH 115) & 1.34 & 1.01 & 1.39 & 1.29 \\
1/4 H & 1.70 & 1.08 & 1.66 & 1.57 \\
(DPH 160) & 1.45 & 0.95 & 1.40 & 1.23 \\
& 1.37 & 0.76 & 1.34 & 1.30 \\
& 1.18 & 0.87 & 1.22 & 1.11 \\
& 1.23 & 0.85 & 1.40 & 1.27 \\
& 1.20 & 0.89 & 1.18 & 1.11 \\
& & & & \\
Average & 1.33 & 0.94 & 1.38 & 1.29 \\
\hline 1/4 HT & 1.09 & 1.09 & 1.13 & 1.13 \\
(DPH 350) & 0.89 & 0.88 & 0.91 & 0.91 \\
& 1.01 & 0.98 & 0.96 & 0.95 \\
& 1.07 & 1.07 & 0.89 & 0.86 \\
& 0.84 & 0.72 & 0.84 & 0.84 \\
\hline Average & 0.98 & 0.95 & 0.95 & 0.94 \\
\hline
\end{tabular}

tion force is proportional to the cross-section area of the wedge times its shear strength. For annealed and $1 / 4-\mathrm{H} \mathrm{Cu}-\mathrm{Be}$ plates tested in vacuum, the absence of oxide contamination permits the prows to continue to grow; in air, equilibrium prow size is reached by approximately the 
15 th revolution when the growth process ceases. At this point, the average coefficient of friction has dropped to about 0.95 ; this agrees with that for the 1/4-HT plates, whose bulk hardness of DPH 350 is the same as the interfacial hardness reached by the annealed and 1/4-H plates.

Thus, there are two competing factors at work, and the equilibrium between them is determined by the test environment for annealed and 1/4-H materials: (1) the decrease in coefficient of friction that results from the increase in plate surface hardness, and (2) the increase in coefficient caused by increasing prow size. From the microhardness-gradient results, the first factor is apparently the same in both air and vacuum, but the second factor is greater in vacuum, leading to greater friction and larger prows.

On the other hand, for $\mathrm{Cu}-\mathrm{Be}$ fully precipitation hardened, the prow-growth factor predominates for all test conditions, and the coefficient of friction increases until the stable prow size is reached and then continues at a steady level for the remainder of the test.

\section{DISCUSSION OF RESULTS}

The friction coefficient of copper on copper was found to be about 2.0 in air and in high vacuum, which agrees with the value of 2.32 found by Buckley (Reference 2) under similar conditions. Other reported friction coefficients of copper on copper ranging from 1.0 in air (Reference 6) to 3.8 in vacuum (Reference 1) probably reflect variations in test conditions and apparatus, making direct comparisons difficult.

The maximum dynamic friction coefficient was found to decrease as the plate hardness increased, which agrees with the results of Buckley (Reference 2) who found that the friction coefficient decreased as hardness increased for several crystallographic orientations of tungsten as well as other inorganic crystals.

Cocks (References 5, 6, 7) describes the formation and growth of wedges or prows at the leading edge of the sliding interface between a hemispherical copper slider and a large-diameter copper drum. Initially a clean polished hemispherical-tipped slider was positioned on the polished drum with a 760-gram normal load. As the drum began to turn with an interface speed of 0.038 $\mathrm{cm} / \mathrm{sec}$, a prow or wedge was formed by cold-welding and grew by continuous shear, thus separating the sliders from the drum. Periodically the prow broke off, reformed, and grew. The prow on the slider increased in height as metal was continuously sheared from the drum and coldwelded to the prow.

The formation and growth of wedges and prows as described by Cocks (References 5, 6, 7) for copper specimens was observed in the present investigation for most tests on copper and $\mathrm{Cu}-\mathrm{Be}$ plates with various slider materials. Early in the test a prow forms, separating the slider from the plate and removing the slider itself from any further interaction with the plate. The prow grows in size and height by continuous work hardening and shear in the metal under the prow. The plastic deformation decreases from a maximum at the plate surface to zero within the bulk 
of the plate. Microhardness measurements (Figures 10 and 11) and slipline observations (Figures 8 and 9) indicate the gradient of deformation and strain hardening occurring in the region of the interface in the slider and the plate. The prow continuously fractures in the weaker metal below the initial interface and thereby collects metal and grows. Occasionally, with slider and plate of similar hardness and work hardening characteristics, the shear process alternates from slider to plate, leading to a laminated prow similar to that shown in Figure 6.

The mechanism of prow formation is the same in air as in vacuum. The increase in friction and wear in vacuum is attributed to the enhancement of growth in the absence of contaminating oxide layers, which in air limit the equilibrium prow size.

The metallographic structure of the prows supports Cocks' suggested mechanism of an initial adhesion between the surfaces involved, followed by continuous shearing at a small angle to the original interface. The inclined area may be seen in Figure 8(a) and (b), although the shearing has extended far beyond this region of prow origin in the case of the slider tested in vacuum. It is interesting to note that the maximum hardness and depth of hardening within the slider are found directly above this region. This was observed for mild steel, annealed, and $1 / 4-\mathrm{H} \mathrm{Cu}-\mathrm{Be}$ sliders tested on all plate materials. Very hard slider materials, such as 1095-steel RC 60 and $\mathrm{Cu}-\mathrm{Be} \mathrm{RC} 38$, show little or no deformation.

\section{CONCLUSIONS}

The results obtained in this friction investigation justify the following conclusions:

1) Coefficient of friction decreases with increasing plate hardness independent of slider hardness for each test pressure investigated.

2) Prow formation arises from initial adhesion of contacting surfaces, and prows subsequently grow by a continuous deformation process involving work hardening and shear below the interface.

3) The mechanism for prow formation is independent of test environment. However, while vacuum promotes prow growth, in air, contamination products (e.g., oxide layers) inhibit growth beyond a certain stable size.

4) Ultimate depth of strain hardening below the track surface and maximum hardness attained were independent of vacuum and prow size for annealed and $1 / 4-\mathrm{H} \mathrm{Cu}-\mathrm{Be}$ plates.

5) Interfacial-surface hardness rather than bulk-plate hardness governs the coefficient of friction. 


\section{ACKNOWLEDGMENTS}

The authors would like to acknowledge the excellent support offered by the following: Dr. Henry E. Frankel, John C. Smith, William B. Latham, and James R. Jarrett, who performed a variety of tasks during the course of this investigation.

Goddard Space Flight Center

National Aeronautics and Space Administration

Greenbelt, Maryland, May 21, 1968

120-34-01-06-51

\section{REFERENCES}

1. Evans, R. M., and Monroe, R. E., "Surface Welding in the Space Environment," DMIC Memo 214, Battelle Memorial Institute, June 9, 1966.

2. Buckley, D. H., "The Influence of Various Physical Properties of Metals on Their Friction and Wear Behavior in Vacuum," Metals Eng. Quart., p. 44, May 1967.

3. Johnson, K. I., and Keller, D. V., Jr., "Effect of Contamination on the Adhesion of Metallic Couples in Ultra-High Vacuum," J. Appl. Phys., 38(4):1896, March 15, 1967.

4. Rabinowicz, E., "Friction and Wear of Metals," Metals Eng. Quart., p. 4, May 1967.

5. Cocks, M., "Interaction of Sliding Metal Surfaces," J. Appl. Phys., 33(7):2152, July 1962.

6. Cocks, M., "Role of Displaced Metal in the Sliding of Flat Metal Surfaces," J. Appl. Phys., 35(6):1807, June 1964 .

7. Cocks, M., "Wear Debris in the Contact Between Sliding Metals," J. Appl. Phys., 29:1609, 1958.

8. Ling, F. F., "Mechanics of Sliding Surfaces," Metals Eng. Quart., p. 1, May 1967.

9. Bowden, F. P., Moore, A. J., and Tabor, D., "The Ploughing and Adhesion of Sliding Metals," J. Appl. Phys., 14:80, Feb. 1943.

10. Keller, D. V., Jr., "Application of Recent Static Adhesion Data to the Adhesion Theory of Friction," in "Physical and Chemical Characteristics of Surface and Interfaces," Part I, ed. V. Weiss et al., Syracuse, New York:Syracuse Univ. Press, 1967.

11. Whitehead, J. R., "Surface Deformation and Friction of Metals at Light Loads," Proc. Roy. Soc. $A, 201: 109,1950$. 
12. Rabinowicz, E., "Friction and Wear of Materials," New York:John Wiley and Sons, 1965.

13. Bowden, F. P., and Tabor, D., "Friction and Lubrication," London:Methuen and Co. Ltd., 1956. 